\title{
MHD and Thermal Dispersion-Radiation Effects on Non-Newtonian Fluid Saturated Non-Darcy Mixed Convective Flow with Melting Effect
}

\author{
B D C N Prasad, ${ }^{*}$ K Hemalatha, ${ }^{\dagger}$ and J Siva Ram Prasad $\ddagger$
}

\begin{abstract}
The problem of mixed convection along a vertical plate in a non-Newtonian fluid saturated non-Darcy porous medium in the presence of melting, thermal dispersionradiation effects for aiding and opposing external flows is analyzed. Similarity solution for the governing equations is obtained for the flow equations in steady state. The equations are numerically solved by using Runge-kutta fourth order method coupled with shooting technique. The effects of melting (M), thermal dispersion (D)radiation $(\mathrm{R})$, inertia $(\mathrm{F})$ and mixed convection $(\mathrm{Ra} / \mathrm{Pe})$ on velocity and temperature distributions are examined in the presence of magnetic parameter $\mathrm{MH}$.
\end{abstract}

Keywords: Porous medium, Non-Newtonian Fluid, Melting, Thermal Dispersion, Radiation

\section{Introduction}

Convection heat transfer in porous media in the presence of melting effect has received some attention in recent years. This stems from the fact that this topic has significant direct application

* Department of Computer Applications, P.V.P. Institute of Technology, Vijayawada; bdcnprasad@gmail.com

t Department of Mathematics, V.R. Siddhartha Engineering College, Vijayawada; hemakphd@yahoo.co.in

‡ Department of Mathematics, V.R. Siddhartha Engineering College, Vijayawada; nanijsrp@yahoo.co.in 
in permafrost melting, frozen ground thawing, casting and bending processes as well as phase change metal. The study of melting effect is considered by many researchers in Newtonian fluids. NonNewtonian power law fluids are so wide spread in industrial process and in the environment. The melting phenomena on free convection from a vertical front in a non- Newtonian fluid saturated porous matrix are analyzed by Poulikakos and Spatz. [1] Nakayama and Koyama [2] studied the more general case of free convection over a non-isothermal body of arbitrary shape embedded in a porous medium. Rastogi and Poulikakos [3] examined the problem of double diffusive convection from a vertical plate in a porous medium saturated with a non-Newtonian power law fluid. Shenoy [4] presented many interesting applications of non-Newtonian power law fluids with yield stress on convective heat transport in fluid saturated porous media. Considering geothermal and oil reservoir engine-ering applications, Nakayama and Shenoy [5] studied a unified similarity transformation for Darcy and non-Darcy forced, free and mixed convection heat transfer in non-Newtonian inelastic fluid saturated porous media. Later Shenoy [6] studied non-Darcy natural, forced and mixed convection heat transfer in non-Newtonian power law fluid saturated porous media.

Effect of melting and thermo-diffusion on natural convection heat mass transfer in a non-Newtonian fluid saturated non-Darcy porous medium was studied by R. R. Kairi and P. V. S. N. Murthy. [7] It is noted that the velocity, temperature and concentration profiles as well as the heat and mass transfer coefficients are significantly affected by the melting phenomena and thermaldiffusion in the medium. The non-linear behavior of nonNewtonian fluids in a porous matrix is quite different from that of Newtonian fluids in porous media. The prediction of heat or mass transfer characteristics for mixed or natural convection of nonNewtonian fluids in porous media is very important due to its practical engineering applications such as oil recovery and food processing. If the temperature of the surrounding fluid is rather high, radiation effects play an important role and this situation does exist in space technology. In such cases, one has to take into account the effect of thermal radiation and mass diffusion. On the other hand it is worth mentioning that heat transfer simultaneous 
radiation and convection is very important in the context of space technology and processes involving high temperatures.

Recently, A.Y. Bakier et al. [8] studied Group method analysis of melting effect on MHD mixed convection flow from a radiative vertical plate embedded in saturated porous medium for Newtonian fluids. He developed linear transformation group approach to simulate problem of hydro magnetic heat transfer by mixed convection along vertical plate in a liquid saturated porous medium in the presence of melting and thermal radiation effects for opposing external flow. He studied the effects of the pertinent parameters on the rate of the heat transfer in terms of the local Nusselt number at the solid-liquid interface. More recently Melting and radiation effects on mixed convection from a vertical surface embedded in a non-Newtonian fluid saturated non-Darcy porous medium for aiding and opposing external flows is analyzed by A. J. Chamka et al. [9] They obtained representative flow and heat transfer results for various combinations of physical parameters.

The present paper is aimed at analyzing the effect of melting and thermal dispersion-radiation on steady mixed convective heat transfer from a vertical plate embedded in a non-Newtonian power law fluid saturated non-Darcy porous medium for aiding and opposing external flows.

\section{Mathematical formulation}

A mixed convective heat transfer in a non-Darcy porous medium saturated with a homogeneous non-Newtonian fluid adjacent to a vertical plate, with a uniform wall temperature is considered. This plate constitutes the interface between the liquid phase and the solid phase during melting inside the porous matrix

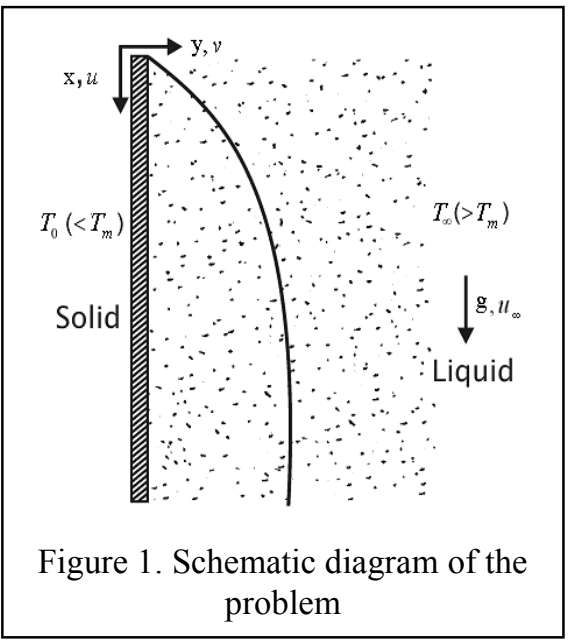


at steady state. The plate is at a constant temperature $T_{m}$ at which the material of the porous matrix melts. Fig. 1 shows the co-ordinate and the flow model. The $\mathrm{x}$-coordinate is measured along the plate and the y-coordinate normal to it. The solid phase is at temperature $\mathrm{T}_{0}<\mathrm{T}_{\mathrm{m}}$. A thin boundary layer exists close to the right of vertical plate and temperature changes smoothly through this layer from $T_{m}$ to $T_{\infty}\left(T_{m}<T_{\infty}\right)$ which is the temperature of the fluid phase.

Taking into account the effect of thermal dispersion the governing equations for steady non-Darcy flow in a non-Newtonian fluid saturated porous medium can be written as follows.

The continuity equation is

$$
\frac{\partial u}{\partial x}+\frac{\partial v}{\partial y}=0
$$

The momentum equation is

$$
\left(\frac{\sigma \mathrm{B}_{0}{ }^{2} \mathrm{~K}}{\rho v}+1\right) \frac{\partial \mathrm{u}^{\mathrm{n}}}{\partial \mathrm{y}}+\frac{\mathrm{C} \sqrt{\mathrm{K}}}{v} \frac{\partial \mathrm{u}^{2}}{\partial \mathrm{y}}=\mp \frac{\mathrm{Kg} \beta}{v} \frac{\partial \mathrm{T}}{\partial \mathrm{y}}
$$

The energy equation is

$$
\mathrm{u} \frac{\partial \mathrm{T}}{\partial \mathrm{x}}+\mathrm{v} \frac{\partial \mathrm{T}}{\partial \mathrm{y}}=\frac{\partial}{\partial \mathrm{y}}\left(\alpha \frac{\partial \mathrm{T}}{\partial \mathrm{y}}\right)-\frac{1}{\rho \mathrm{C}_{\mathrm{p}}} \frac{\partial \mathrm{q}}{\partial \mathrm{y}}
$$

In the above equations, the term which represents the buoyancy forced effect on the flow field has \pm signs. The plus sign indicates aiding buoyancy flow where as the negative sign stands for buoyancy opposed flow. Here $\mathrm{u}$ and $\mathrm{v}$ are the velocities along $\mathrm{x}$ and $\mathrm{y}$ directions respectively, $\mathrm{n}$ is the power-law fluid viscosity index, $\mathrm{T}$ is Temperature in the thermal boundary layer, $\mathrm{K}$ is Permeability, $C$ is Forchheimer empirical constant, $\beta$ is coefficient of thermal expansion, $\mathrm{v}$ is Kinematics viscosity, $\rho$ is Density, $\mathrm{Cp}$ is Specific heat at constant pressure, $\mathrm{g}$ is acceleration due to gravity, $\sigma$ is electrical conductivity, $\mathrm{B}_{0}$ is magnetic field intensity and thermal diffusivity $a=a_{m}+a_{d}$, where $a_{m}$ is the molecular diffusivity and $a_{d}$ is the dispersion thermal diffusivity due to mechanical dispersion. As in the linear model proposed by Plumb[10], the dispersion thermal diffusivity $a_{d}$ is proportional to the velocity component i.e $a_{d}=$ yud, where $\gamma$ is the dispersion coefficient and $d$ is the mean particle diameter. The radiative heat flux term $\mathrm{q}$ is written using the Rosseland approximation (Sparrow and Cess[11], Raptis[12]) as 
MHD and Thermal Dispersion-Radiation Effects Mapana J Sci, 11, 3(2012)

$$
q=-\frac{4 \sigma_{R}}{3 a} \frac{\partial T^{4}}{\partial y}
$$

Where $\sigma_{R}$ is the Stefan - Boltzmann constant and ' $a$ ' is the mean absorption coefficient.

The physical boundary conditions for the present problem are

$$
\begin{gathered}
\mathrm{y}=0, \mathrm{~T}=\mathrm{T}_{\mathrm{m}}, \mathrm{k} \frac{\partial \mathrm{T}}{\partial \mathrm{y}}=\rho\left[\mathrm{h}_{\mathrm{sf}}+\mathrm{C}_{\mathrm{s}}\left(\mathrm{T}_{\mathrm{m}}-\mathrm{T}_{0}\right)\right] \mathrm{v} \\
\text { and } \mathrm{y} \rightarrow \infty, \mathrm{T} \rightarrow \mathrm{T}_{\infty}, \mathrm{u}=\mathrm{u}_{\infty}
\end{gathered}
$$

Where $\mathrm{h}_{\mathrm{sf}}$ and $\mathrm{C}_{\mathrm{s}}$ are latent heat of the solid and specific heat of the solid phases respectively and $\mathrm{u}_{\infty}$ is the assisting external flow velocity, $k=\alpha \rho C_{p}$ is the effective thermal conductivity of the porous medium. The boundary condition (5) means that the temperature on the plate is constant and thermal flux of heat conduction to the melting surface is equal to the sum of the heat of melting and the heat required for raising the temperature of solid to its melting temperature $\mathrm{T}_{\mathrm{m}}$.

Introducing the stream function $\psi$ with $\mathrm{u}=\frac{\partial \psi}{\partial \mathrm{y}}$, and $\mathrm{v}=-\frac{\partial \psi}{\partial \mathrm{x}}$

The continuity equation (1) will be satisfied and the equations (2) and (3) transform to

$$
\begin{aligned}
& \left(\frac{\sigma \mathrm{B}_{0}^{2} \mathrm{~K}}{\rho v}+1\right) \frac{\partial}{\partial \mathrm{y}}\left(\frac{\partial \psi}{\partial \mathrm{y}}\right)^{\mathrm{n}}+\frac{\mathrm{C} \sqrt{\mathrm{K}}}{v} \frac{\partial}{\partial \mathrm{y}}\left(\frac{\partial \psi}{\partial \mathrm{y}}\right)^{2}=\mp \frac{\mathrm{Kg} \beta}{v} \frac{\partial \mathrm{T}}{\partial \mathrm{y}} \\
& \frac{\partial \psi}{\partial \mathrm{y}} \frac{\partial \mathrm{T}}{\partial \mathrm{x}}-\frac{\partial \psi}{\partial \mathrm{x}} \frac{\partial \mathrm{T}}{\partial \mathrm{y}}=\frac{\partial}{\partial \mathrm{y}}\left[\left(\alpha_{\mathrm{m}}+\gamma \frac{\partial \psi}{\partial \mathrm{y}} \mathrm{d}\right) \frac{\partial \mathrm{T}}{\partial \mathrm{y}}\right]+\frac{4 \sigma_{\mathrm{R}}}{3 \rho \mathrm{C}_{\mathrm{p}} \mathrm{a}} \frac{\partial}{\partial \mathrm{y}}\left[\frac{\partial \mathrm{T}^{4}}{\partial \mathrm{y}}\right]
\end{aligned}
$$

Introducing the similarity variables as $\psi=f(\eta)\left(a_{m} u_{\infty} x\right)^{1 / 2}, \eta=\left(\frac{u_{\infty} x}{\alpha_{m}}\right)^{\frac{1}{2}}\left(\frac{y}{x}\right)$, $\theta(\eta)=\frac{T-T_{m}}{T_{\infty}-T_{m}}$, the momentum equation (7) and energy equation (8) are reduced to

$$
\mathrm{n}(1+\mathrm{MH}) \mathrm{f}^{11} \mathrm{f}^{1^{\mathrm{n}-1}}+2 \mathrm{Ff}^{1} \mathrm{f}^{11}=\mp\left(\frac{\mathrm{Ra}_{\mathrm{x}}}{\mathrm{Pe}_{\mathrm{x}}}\right)^{\mathrm{n}} \theta^{1}
$$

and

$\left(1+D f^{1}\right) \theta^{11}+\left(\frac{1}{2} f+D f^{11}\right) \theta^{1}+\frac{4}{3} R\left[\left(\left(\theta+C_{r}\right)^{3} \theta^{11}+3 \theta^{1^{2}}\left(\theta+C_{r}\right)^{2}\right)\right]=0(10)$ where the prime symbol denotes the differentiation with respect to the similarity variable $\eta$ and $\mathrm{MH}=\frac{\sigma \mathrm{B}_{0}{ }^{2} \mathrm{~K}}{\rho v}$ is Magneto Hydro 
Dynamic parameter, $\mathrm{Ra}_{\mathrm{x}} / \mathrm{Pe}_{\mathrm{x}}$ is the mixed convection parameter, $\mathrm{Ra}_{\mathrm{x}}=\frac{\mathrm{x}}{\alpha}\left(\frac{\mathrm{g} \beta \mathrm{k}\left(\mathrm{T}_{\infty}-\mathrm{T}_{\mathrm{m}}\right)}{v}\right)^{\frac{1}{\mathrm{n}}}$ is the local Rayleigh number, $\mathrm{Pe}_{\mathrm{x}}=\frac{\mathrm{u}_{\infty} \mathrm{x}}{\alpha}$ is the local peclet number. $F=f_{0}\left(P e_{d}\right)^{2-n}, f_{0}=\left(\frac{\alpha}{d}\right)^{2-n}\left(\frac{C \sqrt{K}}{v}\right)$ is the nondarcian parameter. $\mathrm{Pe}_{\mathrm{d}}$ is the pore diameter dependent peclet number. $\mathrm{D}=\frac{\gamma d \mathrm{du}_{\infty}}{\alpha_{\mathrm{m}}}$ is the dispersion parameter. $\mathrm{C}_{\mathrm{r}}=\frac{\mathrm{T}_{\mathrm{m}}}{\mathrm{T}_{\infty}-\mathrm{T}_{\mathrm{m}}}$ is the temperature ratio, $R=\frac{4 \sigma_{R}\left(T_{\infty}-T_{m}\right)^{3}}{k a}$ is the radiation parameter.

Taking into consideration, the thermal dispersion effect together with melting, the boundary conditions (5) and (6) take the form

$$
\begin{gathered}
\eta=0, \theta=0, f(0)+\left\{1+\operatorname{Df}^{1}(0)\right\} 2 M \theta^{1}(0)=0 \\
\text { and } \eta \rightarrow \infty, \theta=1, f^{1}=1
\end{gathered}
$$

where $M=\frac{C_{f}\left(T_{\infty}-T_{m}\right)}{h_{s f}+C_{s}\left(T_{m}-T_{0}\right)}$ is the melting parameter.

\section{Solution Procedure}

The dimensionless equations (9) and (10) together with the boundary conditions (11) and (12) are solved numerically by means of the fourth order Runge-Kutta method coupled with double shooting technique. The solution thus obtained is matched with the given values of $f^{1}(\infty)$ and $\theta(0)$. In addition the boundary condition $\eta \rightarrow \infty$ is approximated by $\eta_{\max }=8$ which is found sufficiently large for the velocity and temperature to approach the relevant free stream properties. Numerical computations are carried out for $\mathrm{F}=0$, $0.5,1 ; \mathrm{D}=0,0.5,1 ; \mathrm{Ra} / \mathrm{Pe}=1,2,5 ; \mathrm{M}=0,0.8,2 ; \mathrm{n}=0.5,2.5, \mathrm{R}=0,0.5,1$; $\mathrm{MH}=0,1,5,10 ; \mathrm{Cr}=0.1$.

\section{Results and Discussion}

In order to get clear insight on the physics of the problem, a parametric study is performed and the obtained numerical results are displayed with the help of graphical illustrations. The parameters governing the physics of the present study are the melting $(\mathrm{M})$, the mixed convection $(\mathrm{Ra} / \mathrm{Pe})$, the inertia $(\mathrm{F})$, thermal dispersion (D), and Fluid viscosity index (n), radiation(R), 
temperature ratio $(\mathrm{Cr})$. The numerical computations were carried out for the fixed value of buoyancy parameter $\mathrm{Ra} / \mathrm{Pe}=1$ for both the aiding and opposing external flows. The results of the parametric study are shown in figures 2-22.

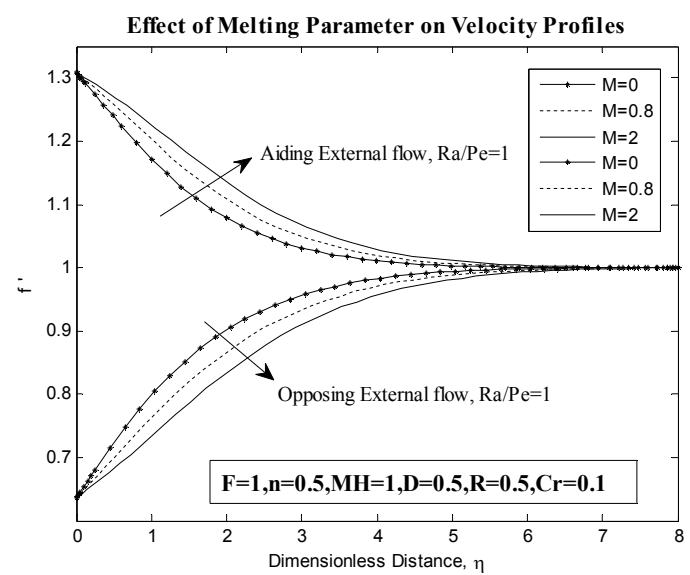

Figure 2

Figure 2 shows the effect of melting parameter $M$ on velocity profiles for both aiding and opposing external flows. It is observed that different behavior exists between the velocity profiles in the presence of solid phase melting effect in the case of aiding and opposing external flows.

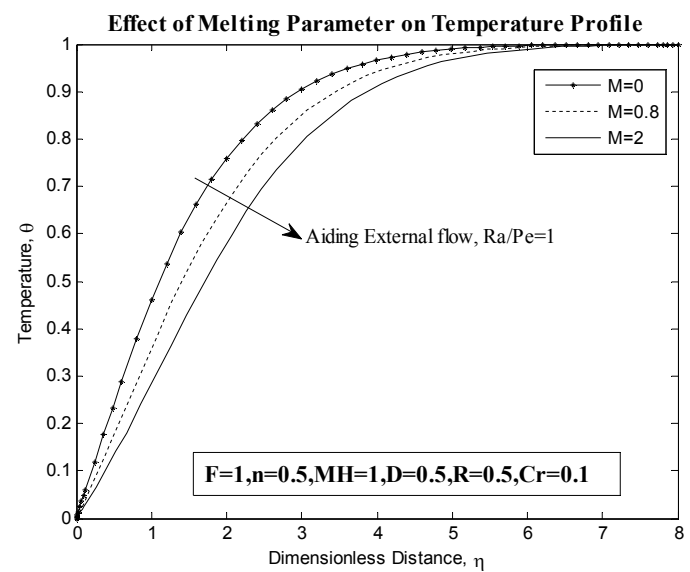

Figure 3 
The increase in the melting parameter $M$ causes the increase of the velocity profiles for the case of aiding flow. Whereas the opposite behavior for the velocity profiles as $\mathrm{M}$ increases is found in the case of opposing flow case.

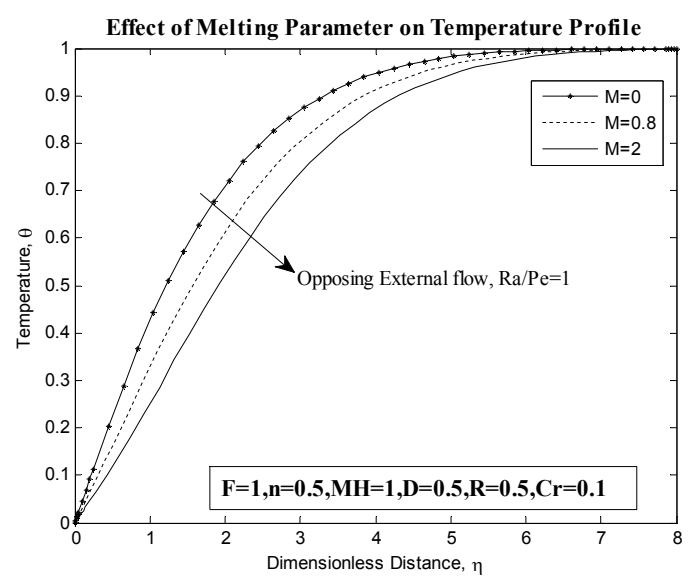

Figure 4

Figure 3 and Figure 4 show the effect of the melting parameter M on temperature distributions for aiding and opposing external flows respectively. It is observed that as increasing the value of the melting parameter $\mathrm{M}$, the temperature distributions decrease for both cases of aiding and opposing external flow conditions.

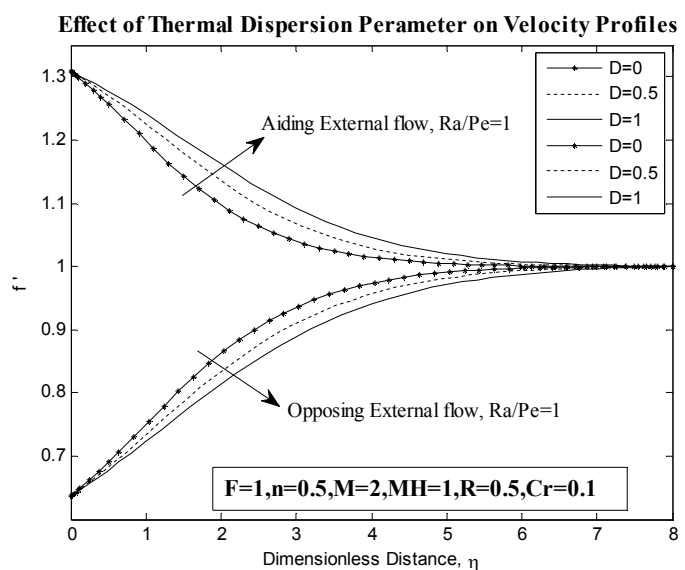

Figure 5 


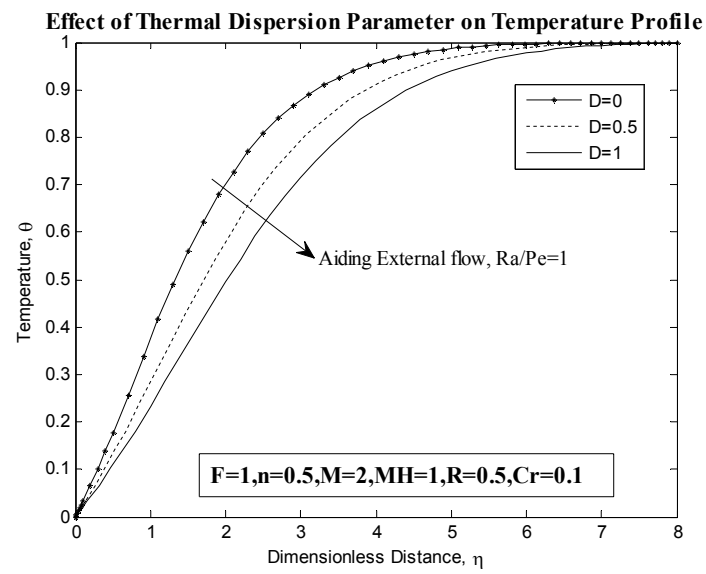

Figure 6

The effects of thermal dispersion parameter $\mathrm{D}$ on the velocity profiles for both cases of aiding and opposing external flow conditions are plotted in Figure 5. It is noted that for the case of aiding flow the velocity profiles increase with increase in the value of D. But this effect is found opposite in the case of opposing flow.

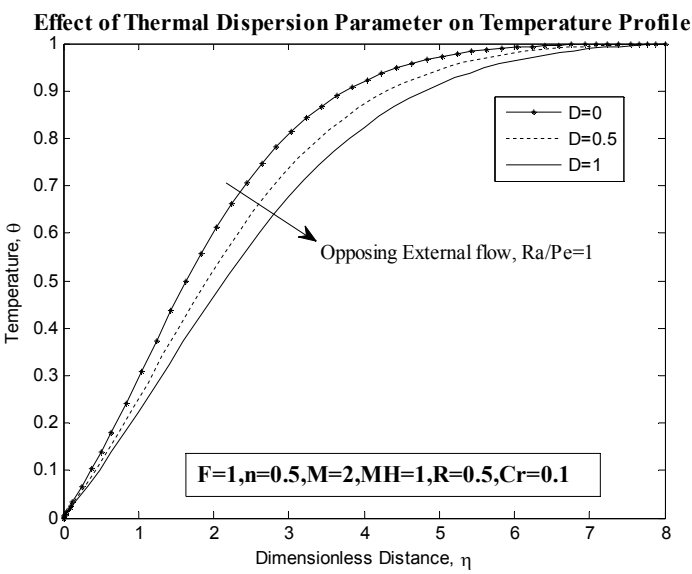

Figure 7

The effects of thermal dispersion parameter $\mathrm{D}$ on temperature distributions for aiding and external flow conditions are plotted in Figure 6 and Figure 7 respectively. It is noted that increasing the values of $\mathrm{D}$ leads to decrease in the liquid temperature distributions in both cases. 


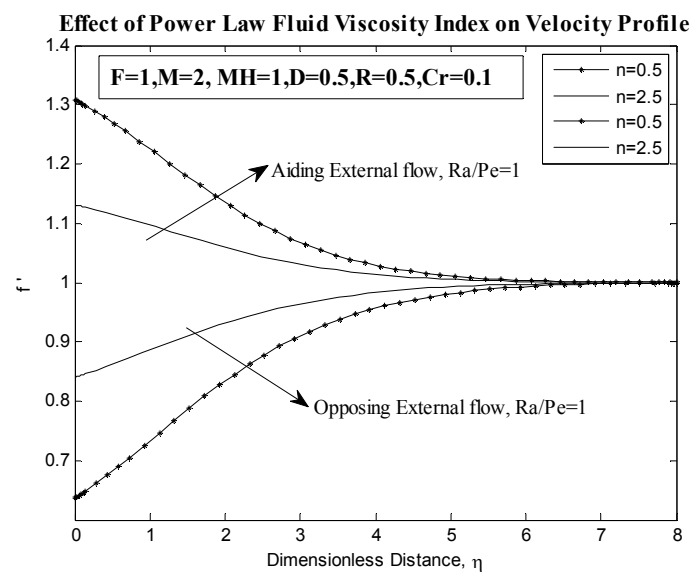

Figure 8

Figure 8 shows the effects of power law fluid viscosity index $\mathrm{n}$ on velocity profiles for both aiding and opposing flow cases. It is observed that in aiding flow case as $\mathrm{n}$ value increases, velocity profiles decreases. Whereas opposite behavior obtained in velocity profiles in opposing flow case.

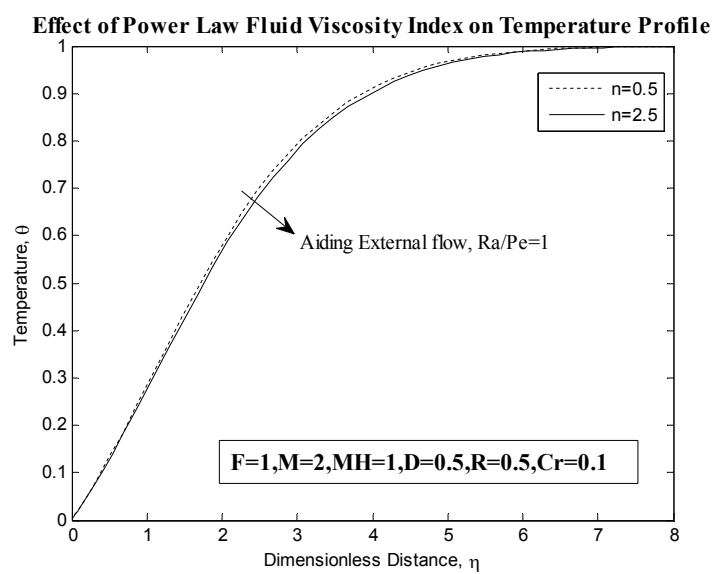

Figure 9

Figure 9 and Figure 10 show the effects of power law fluid viscosity index $\mathrm{n}$ on temperature distributions for both aiding and opposing flow cases respectively. Significant effect is not found. In aiding flow case as $\mathrm{n}$ increases, the temperature distributions decrease. Whereas opposite result is found in opposing flow case. 
MHD and Thermal Dispersion-Radiation Effects $\quad$ Mapana J Sci, 11, 3(2012)

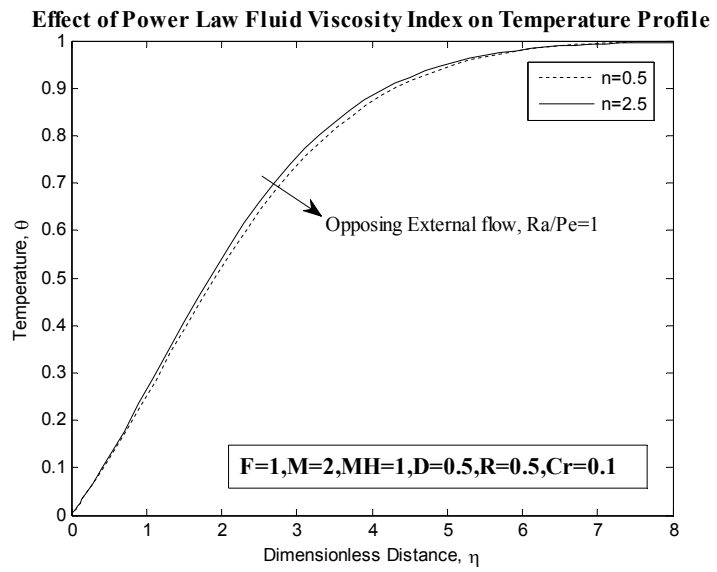

Figure 10

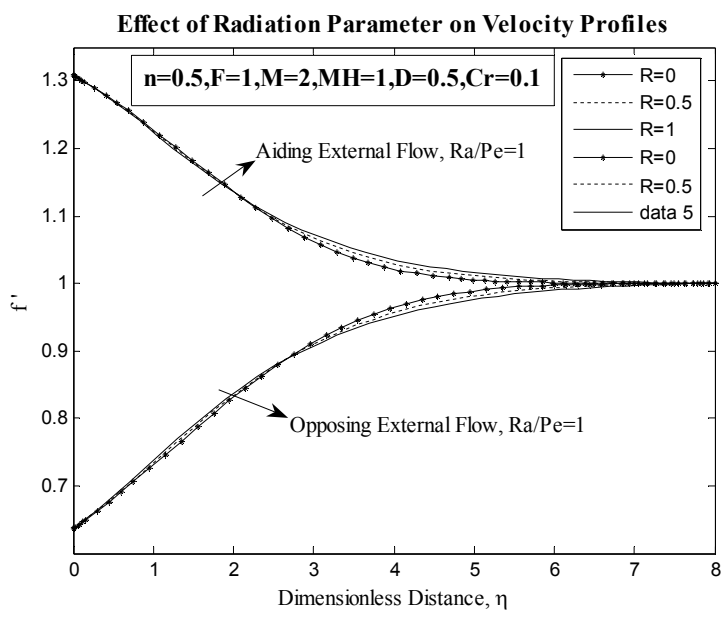

Figure 11

Figure 11 shows the effect of radiation parameter $\mathrm{R}$ on velocity profiles for both aiding and opposing external flows. The increase in the radiation parameter $R$ causes the increase of the velocity profiles for aiding flow case. Whereas in the case of opposing flow the result is found opposite 


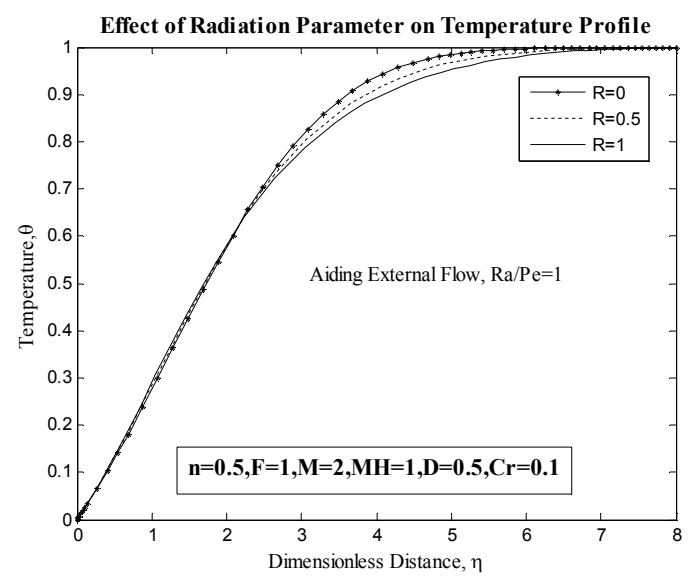

Figure 12

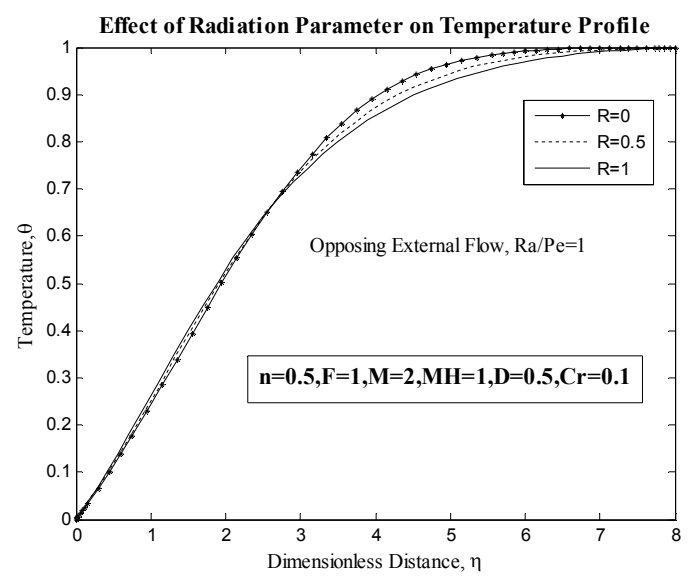

Figure 13

Figure 12 and Figure 13 show the effect of radiation parameter $\mathrm{R}$ on temperature distributions for aiding and opposing external flow conditions respectively. It is observed that same phenomena exist in both cases. As $\mathrm{R}$ increases the temperature distributions decrease for both cases. 
MHD and Thermal Dispersion-Radiation Effects $\quad$ Mapana J Sci, 11, 3(2012)

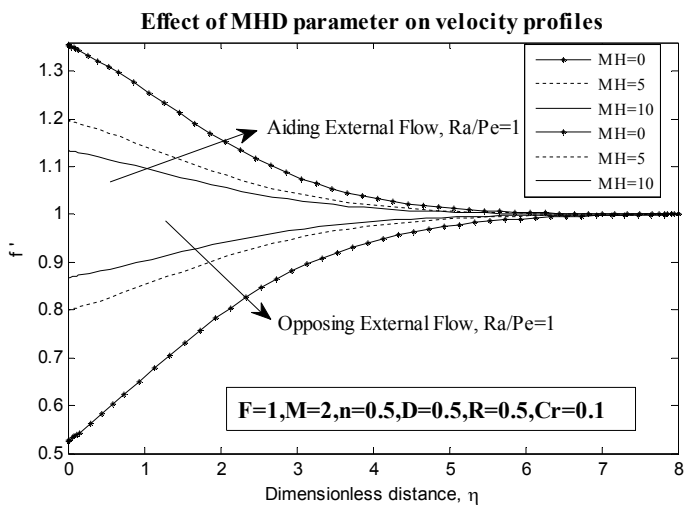

Figure 14

Figure 14 shows the effect of Magneto Hydro Dynamic parameter $\mathrm{MH}$ on velocity profiles for both aiding and opposing flow cases. It is observed that in aiding flow case as $\mathrm{MH}$ value increases, velocity profiles decreases. Whereas opposite behavior obtained in velocity profiles in opposing flow case.

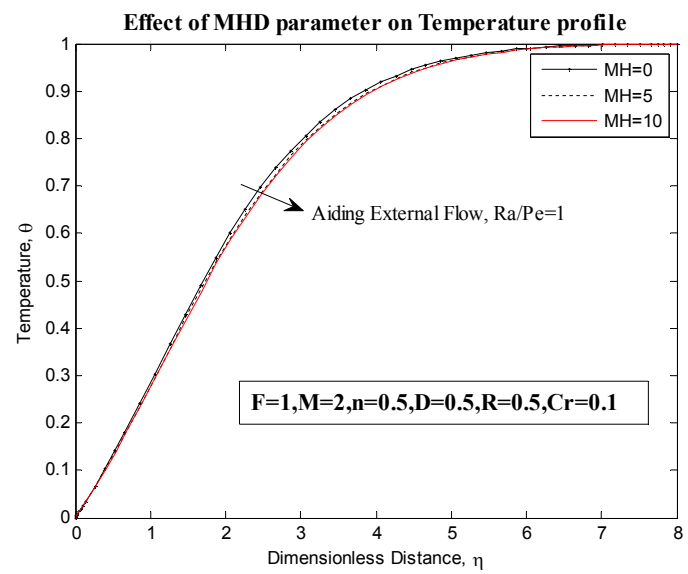

Figure 15 


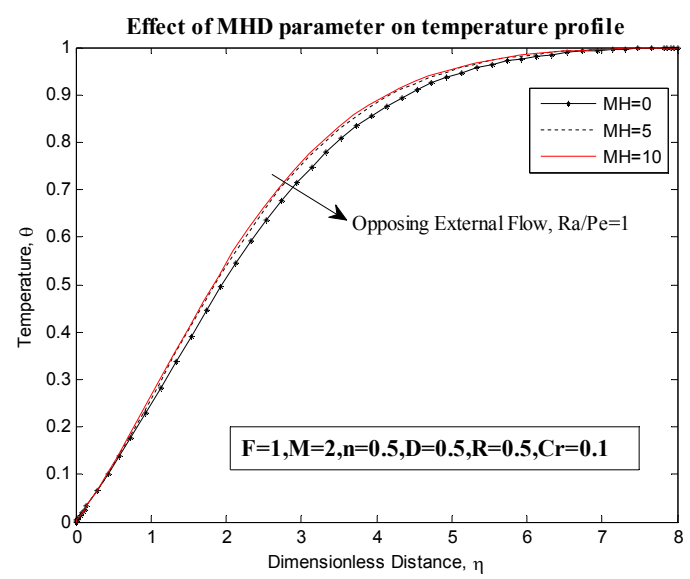

Figure 16

Figure 15 and Figure 16 show the effect of Magneto Hydro Dynamic parameter $\mathrm{MH}$ on temperature distributions for aiding and opposing external flow conditions respectively. In aiding flow case as $\mathrm{MH}$ increases, the temperature distributions decrease. Whereas opposite result is found in opposing flow case.

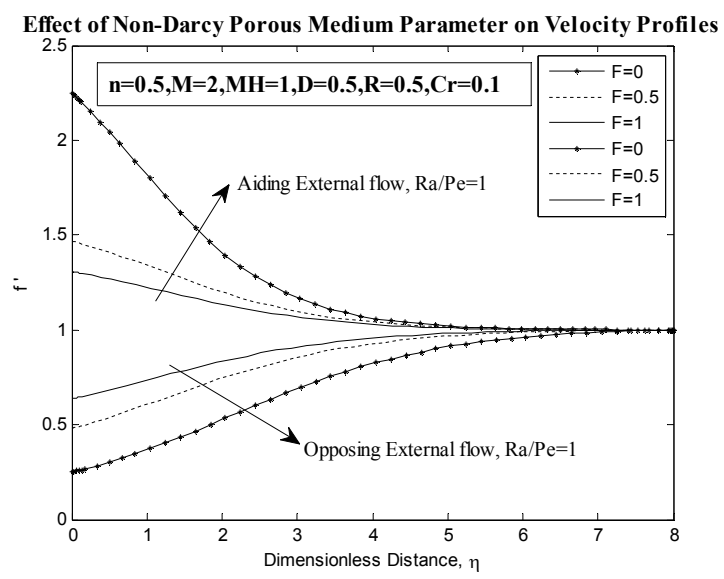

Figure 17

Figure 17 shows the effect of Non-Darcy Porous Medium parameter $\mathrm{F}$ on velocity profiles for both aiding and opposing flow cases. It is observed that in aiding flow case as $F$ value increases, velocity profiles decreases. Whereas opposite behavior obtained in velocity profiles in opposing flow case. 
MHD and Thermal Dispersion-Radiation Effects $\quad$ Mapana J Sci, 11, 3(2012)

Figure 18 and Figure 19 show the effect of Non-Darcy Porous Medium parameter $\mathrm{F}$ on temperature distributions for aiding and opposing external flow conditions respectively. In aiding flow case as $\mathrm{F}$ increases, the temperature distributions decrease. Whereas opposite result is found in opposing flow case.

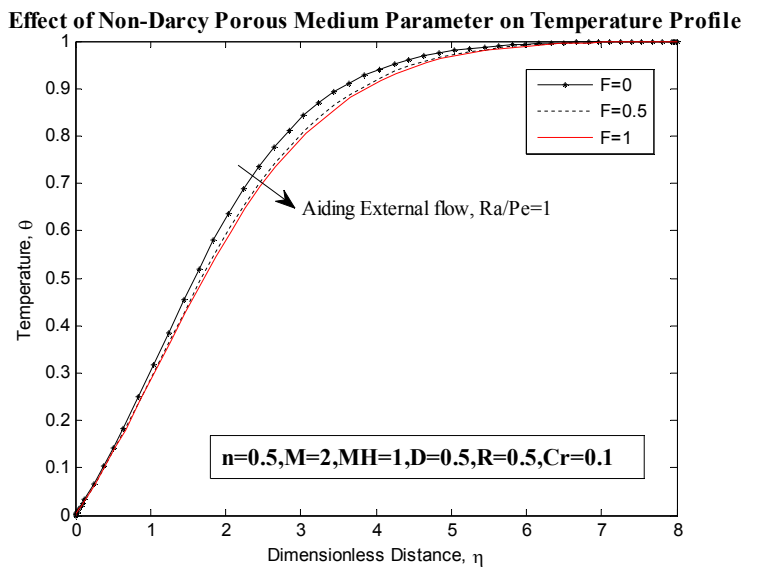

Figure 18

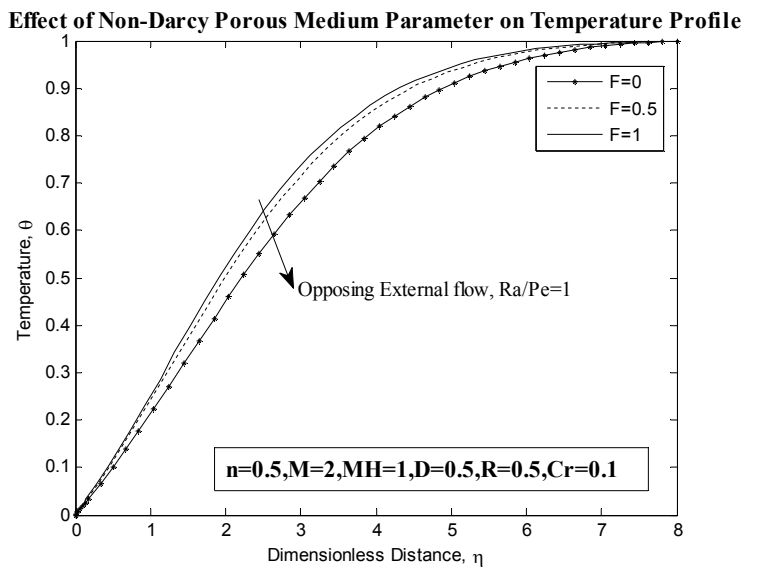

Figure 19 


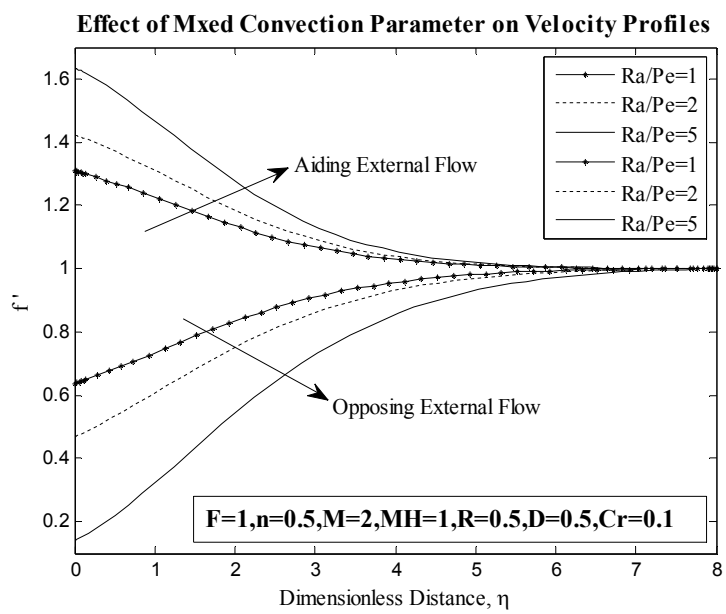

Figure 20

Figure 20 shows the effect of Mixed Convection parameter $\mathrm{Ra} / \mathrm{Pe}$ on velocity profiles for both aiding and opposing flow cases. It is observed that in aiding flow case as $\mathrm{Ra} / \mathrm{Pe}$ value increases, velocity profiles increases. Whereas opposite behavior obtained in velocity profiles in opposing flow case.

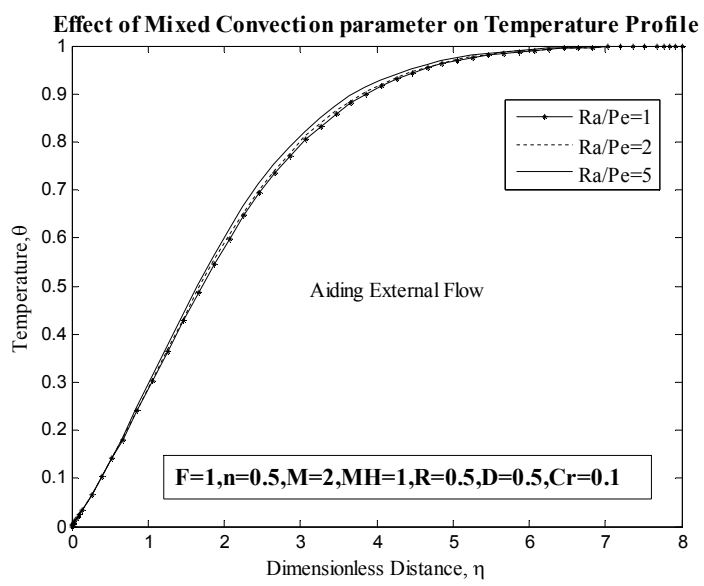

Figure 21 


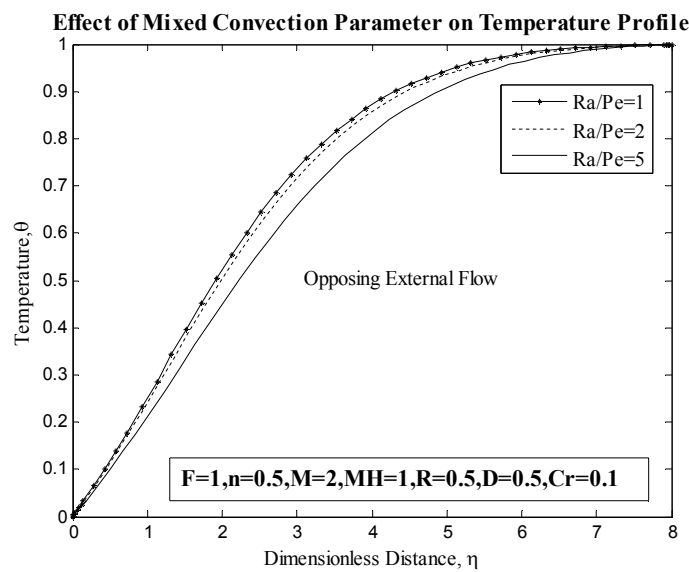

Figure 22

Figure 21 and Figure 22 show the effect of Mixed Convection parameter $\mathrm{Ra} / \mathrm{Pe}$ on temperature distributions for aiding and opposing external flow conditions respectively. In aiding flow case as $\mathrm{Ra} / \mathrm{Pe}$ increases, the temperature distributions increase. Whereas opposite result is found in opposing flow case.

\section{References}

[1] D Poulikakos and T L Spatz, Non-Newtonian natural convection at a melting front in a permeable solid matrix, Int. Commun. Heat and Mass Transfer, vol. 15, pp. 593-603, 1988.

[2] A Nakayama and H Koyama, Buoyancy induced flow of nonNewtonian fluids over a non isothermal body of arbitrary shape in a fluidsaturated porous medium, Appl. Scientific Research, vol. 48, pp. 55-70, 1991. [3] S K Rostagi and D Poulikakos, Double-diffusion from a vertical surface in a porous region Saturated with a non-Newtonian saturated with a nonNewtonian fluid, Int. J. Heat Mass Transfer, vol. 38, pp. 935-946, 1995.

[4] A V Shenoy, Non-Newtonian fluid heat transfer in a porous media, Advances in Heat transfer, vol. 24, pp. 101-190, 1994.

[5] A Nakayama and A V Shenoy, A unified similarity transformation for Darcy and non-Darcy forced, free and mixed convection heat transfer in non-Newtonian inelastic fluid saturated porous media, The Chemical Eng. J., vol. 50, pp. 33-45, 1992.

[6] A V Shenoy, Darcy-Forchheimer natural forced and mixed convection heat transfer in Non-Newtonian power law fluid saturated porous media, Transport in Porous Media, vol. 11, pp. 219-241, 1993. 
[7] R R Kairi and P V S N Murty, Effect of melting and thermo-diffusion on natural convection heat mass transfer in a non-Newtonian fluid saturated non-Darcy porous medium, The Open Transport Phenomena J., vol. 1, pp. 7-14, 2009.

[8] A Y Bakier et al., Group method analysis of melting effect on MHD mixed convection flow from radiate vertical plate embedded in a saturated porous media, Commun. Nonlinear Sci. and Numerical Simulation, vol. 14, pp. 2160-2170, 2009.

[9] A J Chamkha et al., Melting and radiation effects on mixed convection from a vertical surface embedded in a non-Newtonian fluid saturated non-Darcy porous medium for aiding and opposing external flows, Int. J. Phy. Sci., vol. 5, pp.1212-1224, 2010.

[10] O A Plumb, The effect of thermal dispersion on heat transfer in packed bed boundary layers, Proc. $1^{\text {st }}$ ASME/JSME Thermal Eng. Joint Conference, 2, pp. 17-21, 1983.

[11] E M Sparrow and R D Cess, Radiation Heat Transfer, Washington: Hemisphere, 1978.

[12] A Rapits, Radiation and free convection flow through a porous medium, Int. Commun. Heat Mass Transfer, vol. 25, pp.289-295, 1998.

[13] W T Cheng and C H Lin, Melting effect on mixed convection heat transfer with aiding and opposing flows from the vertical plate in a liquid saturated porous medium, Int. J. Heat Mass Transfer, vol. 50, pp. 3026-3034, 2007. 